Editorial

\title{
Looking beyond the fisheries crisis: Cumulative learning from small-scale fisheries through diagnostic approaches
}

\section{A R T I C L E I N F O}

\section{Keywords:}

Social-ecological systems

Small-scale fisheries

Human dimensions

Sustainability

Diagnostic framework

Governance

\begin{abstract}
A B S T R A C T
The common scientific and media narrative in fisheries is one of failure: poor governance, collapsed stocks, and vanishing livelihoods. Yet, there are successful fisheries - instances where governments and/ or communities have maintained or rebuilt stocks, where fishers have robust livelihoods, and where institutions are strong. Scientists and managers alike are becoming increasingly interested in moving beyond the doom-and-gloom stories of fisheries failures toward cumulative knowledge for making fisheries governance more successful. Recent literature has attempted to determine what separates the successes from the failures and better understand how lessons learned for effective fisheries governance can be cumulatively compiled. In this special issue, we present a range of fisheries studies from around the world - Latin America, The Pacific, and East Africa. The studies look at varying fisheries outcomes, including sustainability, cooperation, self-governance, and sustaining livelihoods. The contributions in this special issue all tackle the challenge of exploring, testing, and refining the Diagnostic Framework for Analyzing Social-Ecological Systems developed by Elinor Ostrom as a way to cumulate knowledge on the potential conditions that could be causing a problem or creating a benefit in the governance of smallscale marine fisheries. These articles successfully explore the applicability and contributions of the framework while providing important theoretical refinements for small-scale fisheries.
\end{abstract}

(c) 2013 Published by Elsevier Ltd.

\section{Introduction}

For many decades, fisheries management focused on achieving maximum sustainable yield through top-down management. These top-down policies were often prescribed without consideration of local social or political contexts, often resulting in unsustainable fisheries. Considerable contemporary fisheries literature is focused on documenting how equilibrium-based policies caused widespread changes to marine ecosystems and the coastal societies that depend on them. A common narrative is that fisheries have failed, overfishing is rampant, and people are generally unable to overcome the 'tragedy of the commons' (Mora and Sale, 2011; Worm et al., 2006). However, there is increasing recognition among researchers of the different processes that allow fisheries to modify their own governance landscapes and overcome tragedies of the commons (e.g., Cinner et al., 2012a; Gelcich et al., 2010; Hilborn et al., 2003). As a result, there is increasing awareness of the diversity of governance arrangements - which include the structures and decision-making processes by which people in societies shape outcomes about fisheries - that can bring about positive outcomes. Thus, we are experiencing a revival in recognition of the role of existing common property institutions, decentralized management, and increased empowerment of local authorities and fishers to pursue key social goals such as wellbeing and equity. Additionally, there has been increasing integration of fish stock management and wider environmental governance such as habitat management and restoration, rare species conservation, and incorporation of non-consumptive uses of aquatic biodiversity. Thus, some fisheries are better suited toward social and/or ecological sustainability, paving the way for a more nuanced understanding of how to achieve desirable fisheries outcomes (McClanahan et al., 2009).

Despite real gains in understanding the drivers of sustainability, drawing common lessons among fisheries successes and failures has been difficult. The tendency for high profile journals and the media to focus on disaster narratives have made it difficult for scientists to get traction with success stories, creating strong incentives to report on global declines rather than successes. The 10 most cited fisheries papers of the past 20 years have almost all focused on decline (ISI Web of Knowledge search using the keyword "fisheries"). In addition, disciplinary silos, lack of a common language, and a scarcity of integrated methodology have created fundamental limitations in how science has been able to learn by combining information from case and comparative studies generated at different spatial and temporal scales.

In 2007, Elinor Ostrom, published "A Diagnostic Approach for Going beyond Panaceas," a framework for making inferences from comparative social-ecological studies (Ostrom, 2007). This diagnostic framework drew from a series of carefully controlled laboratory experiments of appropriation dilemmas, targeted 
empirical case studies, previous frameworks and meta-analyses from the published literature, which altogether signaled the basic attributes critical for the emergence and sustainability of common pool resource management. The ultimate goal was to initiate the process of establishing comparable databases to enhance the gathering of research findings about processes affecting the sustainability of common pool resources around the world (Ostrom, 2009). As Ostrom (2009) points out "Research across disciplines and questions will thus cumulate more rapidly and increase the knowledge needed to enhance the sustainability of complex social ecological systems". Articles in this special issue embrace the challenge of knowledge accumulation by using the framework to link fisheries studies in a comparable way. Indeed, this special issue, which attempts to advance the use of the diagnostic framework for analyzing social-ecological systems, is dedicated to the memory of the late Elinor Ostrom. The interdisciplinary nature of this special issue is in recognition of the profound contributions she has made to the hearts and minds of researchers such as ourselves in fields as diverse as ecology, economics, political science, and geography.

In this special issue, we present a range of case studies and comparative analyses detailing the institutional and contextual conditions determining small-scale fishery social and ecological outcomes at a range of spatial and temporal scales. We use Ostrom's diagnostic framework to conceptually organize and unify the papers (Ostrom, 2007, 2009). The framework provides a common language to describe our methods and understand our results. It acts as a lens through which to view a compilation of fisheries determinants of specific outcomes and move beyond case studies, beyond disciplinary viewpoints, and beyond one-size-fitsall panaceas and toward cumulative knowledge. The special issue can also be understood as a portfolio of examples of different analytical approaches with which Ostrom's diagnostic framework can be engaged to study the determinants of social and ecological sustainability.

Here, we first outline Ostrom's diagnostic framework, discussing its strengths and weaknesses. Next, we discuss the individual lessons drawn from each of the studies in this special issue. Finally, we integrate results across studies to understand the broad and contextual conditions that lead to fisheries success and failure, making recommendations for applying this research across the broader seascape.

\section{A diagnostic framework for analyzing Social-Ecological Systems}

There is widespread recognition that human activities are generating dramatic ecological change (Jackson et al., 2001; Rockström et al., 2009), with increasing recognition among scientists and managers that social, economic, and cultural drivers often interact with ecological processes as linked Social-Ecological Systems (Berkes et al., 2003; Berkes and Folke, 1998). The need to understand social-ecological processes is particularly acute among common-pool resources such as shared grazing areas, groundwater basins, irrigation systems, forests, and fisheries, due to their importance as resources and for livelihoods.

Common pool resources have two defining characteristics: they have limited excludability and high subtractability (Ostrom and Ostrom, 1977). Limited excludability means it is costly to keep individuals from harvesting the resources. High subtractability means that when one resource user harvests a resource unit, that resource unit is not available for others to harvest. These two characteristics make common pool resources particularly susceptible to situations that encourage users to overexploit, sometimes to the point of ecological collapse. Prominent examples include ocean fisheries during the late 20th century (Hilborn et al., 2003), which collapsed due to factors such as a lack of appropriate institutions or enforcement (Ostrom, 2008) and the life history characteristics of the species harvested (Myers and Worm, 2003).

Despite the potential for resource overexploitation, many small-scale fisher groups among other local groups have developed norms and rules that enable them to successfully manage common pool resources (see the Digital Library of the Commons http:// dlc.dlib.indiana.edu/dlc/). Such successes have occurred particularly among common pool resource users with local knowledge of the dynamics of the resource and autonomy to design a diverse range of mechanisms to overcome commons dilemmas. Studies of these interactions have led to a rich case study literature that has greatly informed our understanding of social and institutional mechanisms that can enable successful governance of common pool resources (e.g., Basurto, 2005; see the Digital Library of the Commons http://dlc.dlib.indiana.edu/dlc/, Gelcich et al., 2006). A distinct yet complementary series of comparative studies have also identified common principles that lead to successful or failed governance of common pool resources (Cinner et al., 2012b; Cox et al., 2010; Gutierrez et al., 2011; McClanahan et al., 2006).

A large body of theoretical, case study, and comparative research has uncovered a set of potential variables, operating at multiple scales, that relate to common pool resource governance outcomes. A coherent way to navigate this maze of potential relationships is through development of a conceptual, ontological framework that helps to organize relationships among the many concepts or variables; posit how they are causally related across and among scales; define how and where these variables are embedded within the system; and discern how sub-systems are linked to still larger systems. Such an ontological system also addresses the problem of infinite regress, where a linguistic construction such as a concept is composed of sub-concepts, which are in turn composed of sub-concepts, and further sub-concepts.

Here, we draw on the multitier framework for analyzing socialecological systems presented in Proceedings of the National Academy of Sciences on "A Diagnostic Approach for Going beyond Panaceas" (Ostrom, 2007) and Ostrom (Ostrom, 2007) (Fig. 1). The framework starts with a first tier of variables that those studying common pool resources can use in any particular focal system, ranging in scale from a small inshore fishery to the global commons. These first-tier core subsystems include: the social, economic, and political setting (S); resource system (RS); governance system (GS); resource units (RU); actors (A); interactions (I); and outcomes $(\mathrm{O})$, as well as related ecosystems (ECO) (Ostrom, 2009). To apply the framework, a researcher would first identify the Resource System (RS) and Resource Units (RU) relevant for answering a particular question and use these as the focal system for analysis. The diagnostic framework represents each of these broad components as a unified ontological system, providing physical bounds and a critical point of departure for the analysis process.

To diagnose the causal patterns that affect specific outcomes, such as successful formation of self-organization to control access to fishing grounds, one needs to incorporate a set of "second-tier" variables (Table 1) that are contained within the broadest tiers identified in Fig. 1. The list of second-tier variables in Table 1 constitutes an initial effort to help group and classify important variables into a tiered ontology specific to the theoretical puzzles related to common pool resource problems such as the one posited above. Although comprehensive, the framework itself isn't final at any point; rather it forms a sound basis from which further concepts and ideas can be integrated and tested. Progress in the development of this tiered ontology leads to better understanding of how concepts are embedded and related with each other, opening space for third, fourth, and fifth tiers to be further elucidated (Basurto et al., this issue). 
Social. Economic, and Political Settings (S)

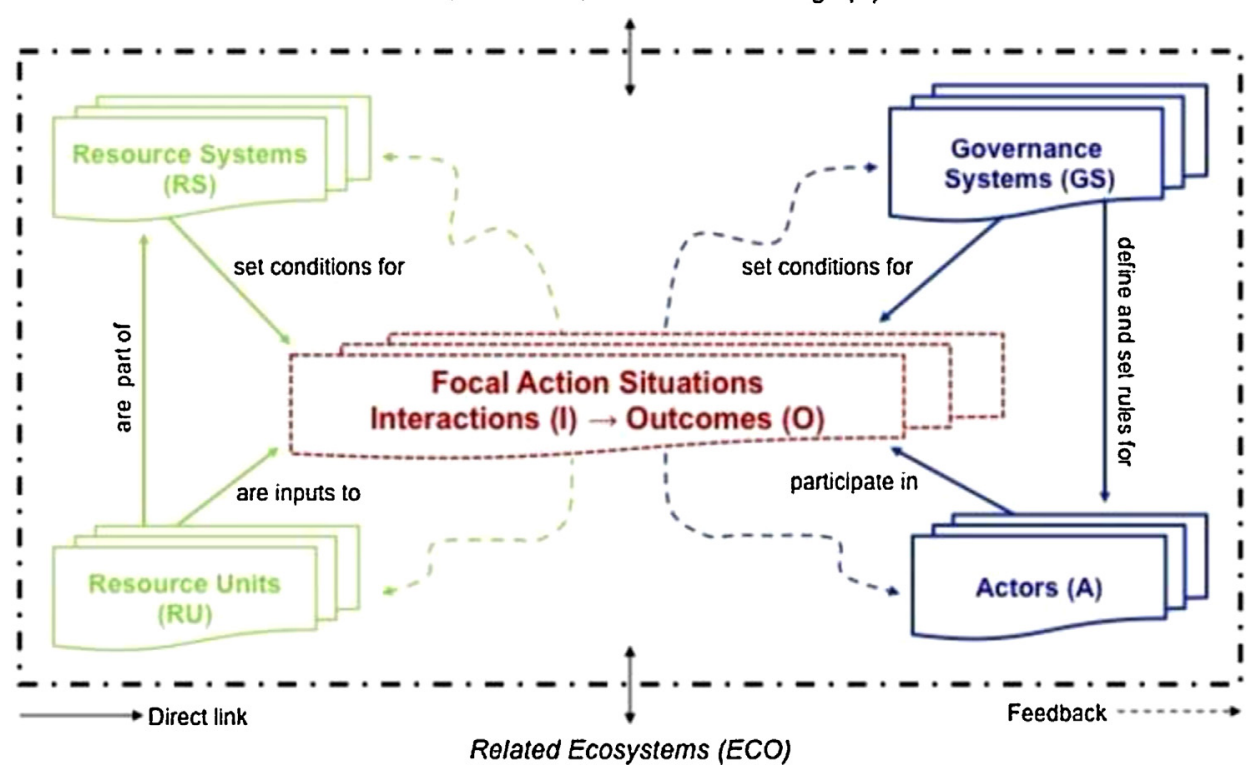

Fig. 1.

Table 1

Social; Economic; and Political Settings (S)

S1- Economic development. S2- Demographic trends. S3- Political stability. S4- Other governance systems.

S5- Markets. S6-Media organizations. S7-Technology.

Resource Systems (RS)

RS1- Sector (e.g.; water; forests; pasture; fish)

RS2- Clarity of system boundaries

RS3- Size of resource system

RS4- Human-constructed facilities

RS5- Productivity of system

RS6- Equilibrium properties

RS7- Predictability of system dynamics

RS8- Storage characteristics

RS9- Location

Resource Units (RU)

RU1- Resource unit mobility

RU2- Growth or replacement rate

RU3- Interaction among resource units

RU4- Economic value

RU5- Number of units

RU6- Distinctive characteristics

RU7- Spatial and temporal distribution
Governance Systems (GS)

GS1- Government organizations

GS2- Nongovernment organizations

GS3- Network structure

GS4- Property-rights systems

GS5- Operational-choice rules

GS6-Collective-choice rules

GS7-Constitutional-choice rules

GS8- Monitoring and sanctioning rules

Actors (A)

A1- Number of relevant actors

A2-Socioeconomic attributes

A3- History or past experiences

A4- Location

A5- Leadership/entrepreneurship

A6- Norms (trust-reciprocity)/social capital

A7- Knowledge of SES/mental models

A8- Importance of resource (dependence)

A9- Technologies available

Action Situations: Interactions (I) $\rightarrow$ Outcomes (O)

Activities and Processes:

I1- Harvesting

12- Information sharing

13- Deliberation processes

14- Conflicts
Outcome Criteria:

01-Social performance measures

(e.g.; efficiency; equity; accountability; sustainability)

O2- Ecological performance measures

(e.g.; overharvested; resilience; biodiversity; sustainability)

I5- Investment activities

I6- Lobbying activities

O3- Externalities to other SESs

17- Self-organizing activities

18- Networking activities

19- Monitoring activities

I10- Evaluative activities

Related Ecosystems (ECO)

ECO1- Climate patterns. ECO2- Pollution patterns. ECO3- Flows into and out of focal SES.

Please cite this article in press as: Cinner, J.E., et al., Looking beyond the fisheries crisis: Cumulative learning from small-scale fisheries through diagnostic approaches. Global Environ. Change (2013), http://dx.doi.org/10.1016/j.gloenvcha.2013.11.001 
Integrated analysis of SESs have been hindered in part by academic, theoretical, and governance distinctions in training, data collection, and mandate that make the social and ecological dimensions seem both incompatible and incomparable (Gibson, 2006). While many of these distinctions reflect real differences between human-social and ecological phenomena, they also fail to recognize the relationships among them. Ostrom's framework helps to bridge these gaps by:

(1) Establishing a common language that promotes mutual understanding. Different social science disciplines and ecologists bring their own methods, ideas, and language to bear on resource problems and the inability to communicate often limits the effectiveness of interdisciplinary work.

(2) Setting SES bounds and deciding which potential components are relevant to a given study or research question. By providing a comprehensive list of factors that can be examined to determine which components are relevant to the local context and the research question, a diagnostic framework greatly aids the process of variable selection, allowing researchers to focus on how each tiered factor might be best represented in their local context and data.

(3) Defining the multi-level structure of social-ecological problems. Social-ecological systems include multiple components operating at multiple scales. The imposition of constraint by upperlevel (larger-scale) attributes on lower-level (smaller-scale) factors is an almost universal characteristic of complex systems (Allen and Starr, 1982) and Ostrom's framework recognizes these relationships explicitly, allowing higher and lower tier variables to interact. Horizontal interactions represent relationships between components occurring at the same spatial, temporal, or organizational scale, whereby the effect of one SES factor is mediated by the value of another within the same tier. Such interactions help explain why, for example, a response for particular kinds of users might change given different personal circumstances. Vertical interactions on the other hand, occur when factors at a higher scale affect factors at lower scale tier. These interactions help explain why the importance of personal attributes such as of social status may vary among communities.

When in place, a common language, defined boundaries, and a clear structure help make SES problems tractable. This approach recognizes that, while each case is unique, there exists a diagnostic set of general social-ecological elements that help to explain common pool resource success or failure. This use of general elements to describe an incomplete or imperfectly observed system is also the basis of statistical inference (Gelman and Hill, 2007), supporting the use of Ostrom's diagnostic framework as an empirical basis for quantifying SESs.

Building ontologies to diagnose policy problems and to design empirical research is a necessary step toward developing better conceptual language and theory. It is important to understand, however, that an analyst does not need to include the fifty or more potential variables outlined in the framework to study common pool resources. Few would develop a theory or do empirical research that simultaneously includes all of the second-tier (or lower) variables that may lead to particular interactions and outcomes. Rather the intention of the framework is to enable researchers, officials, and citizens to understand the potential set of variables and sub-variables that could be causing a problem or creating a benefit. Clearly, not all components apply to every social-ecological system, and elements can readily be used or discarded according to need; in this way diagnostic frameworks are decomposable, i.e. capable of being trimmed of superfluous elements for a given application.
Like any analytical tool, the diagnostic framework has clear strengths and weaknesses. The social-ecological system framework is primarily useful in helping organize the study of socialecological systems. Yet, social scientists often shy away from attempting to build or advocate classificatory systems or frameworks because they necessarily imply a certain worldview and the normative values held within such worldview. As such, these systems run the risk of creating blind spots toward other worldviews and the values that they represent. For example, there are certain issues critical to the sustainability of commons governance, such as power dynamics between stakeholders (e.g., Crona and Bodin, 2010; Basurto et al., this issue), which are difficult to address using Ostrom's framework. Thus, there is a danger that certain perspectives or types of studies may get minimized or ignored by those using Ostrom's framework. In developing theoretical understanding of social-ecological system components, it is important to realize that, while every case and human being are unique, humans share some common attributes. The challenge is to determine what attributes or variables are important at any one time and whether they apply in general. This is a problem the medical profession has been struggling with for many years, leading to the slow development of diagnostic theory that has enabled medicine to move beyond panaceas. It is diagnostic theory that enables medical practitioners to dig into the very large number of elements that characterize all humans to determine the specific combination elements causing a particular medical problem. This mirrors precisely the goal of Ostrom's socialecological system framework.

So, how can we start moving toward a diagnostic theory for the analysis of coastal social-ecological systems? In the following section, we provide an overview for how analysts in this special issue have used the diagnostic framework to understand how resource users can create the conditions for institutional change and overcome collective-action dilemmas.

\section{Lessons from coastal social-ecological systems}

This special feature of Global Environmental Change consists of four contributions that highlight how Ostrom's diagnostic framework can be used to help empirically analyze and compare case studies, identify determinants of sustainability and cooperation, and inform methods for linking social and ecological systems. The four articles in this special issue use qualitative and quantitative analyses, range from case studies to large-scale studies, to explore commons issues across spatial or temporal scales.

All four articles highlight people's capacity to overcome potential fisheries crises in a decentralized management context where there are governance systems in place that allow people to make or modify the rules to better suit local conditions. Importantly, though, not all examples in the special issue were successful, and many of the articles focus on lessons that can be learned by comparing successes and failures. For example, Basurto et al. (this issue) use a comparative case study approach to examine outcomes from benthic fisheries in Mexico and Chile. They highlight several cases where people have effectively organized under challenging circumstances to avoid commons dilemmas, resulting in both social benefits and sustainable fisheries. Notably, they also detail cases where people were unable to collectively organize to overcome commons dilemmas. Earnst et al. (this issue) describe how a lobster fishery on a remote Chilean island can sustain harvests over multiple generations, despite the lack of conventional harvesting controls. MacNeil and Cinner (this issue) highlight how co-management arrangements can provide critical livelihood benefits to resource users. They use a hierarchical modeling approach to conduct one of the most comprehensive 
quantitative analyses using Ostrom's diagnostic framework. They examine how 16 social and institutional conditions are related to livelihood outcomes across 42 co-management arrangements in five Indo-Pacific countries. Finally, Aswani et al. (this issue) use an experimental economics approach to explore cooperation among fishers in the Solomon Islands. They highlight how cooperative behavior among fishers can be very different from the purely selfinterested rational actor that Hardin's tragedy of the commons would predict. Together, the articles in this special issue highlight three key themes relevant to enhancing the sustainability of marine social-ecological systems.

First, the authors highlight how key social and institutional conditions can influence primary fisheries outcomes such as cooperation, sustainability, and livelihood benefits. The Chilean and Mexican case studies in Basurto et al. highlight the important role of property rights that allow restricted access, high levels of dependence on resources, leadership, social capital (specifically trust and reciprocity), and monitoring of the ecosystem. Using Ostrom's framework, Earnst et al. highlight how the sustainability of the lobster fishery is facilitated by key aspects of the Resource System (RS) itself (specifically, a productive stock, clearly defined boundaries, and the ability to partition fishing grounds among resource users), key characteristics of the Actors (A) (including high levels of dependence on the resource, extensive local ecological knowledge, and a relatively small population of resource users), the Governance System (GS) which allowed for de facto marine tenure and simple operational rules to be developed, and finally, critical interactions that facilitated self-organization and the development of key partnerships.

The quantitative analysis by MacNeil and Cinner reveals that Actors (A) were more likely to perceive benefits from comanagement when they are more involved in decisions, were aware that humans are causal agents of change in marine systems, were wealthier, were not migrants, were in villages with smaller populations and older co-management arrangements, and when the Governance System (GS) had clearly established boundaries. Yet MacNeil and Cinner dig deeper by quantifying how critical interactions between wealth, dependence on resources, and involvement in decision-making, affect livelihood outcomes in co-management. Among the key findings of this novel analysis is that involvement in decision-making can increase the probability of beneficial livelihood outcomes threefold for the poor.

In a novel application of a public goods game tailored to mimic the problem of common pool fisheries management, Aswani et al. examine fishers' willingness to contribute to public goods despite incentives to free ride. They used Ostrom's framework to guide their analysis of how individual-scale variables (e.g., age, education, family size, ethnicity, occupational status, personal norms), in the context of village-scale variables (e.g., village, governance institutions, group coercive action), influence cooperative behavior, as indexed by game contributions. They find that age, beliefs about whether outsiders should be able to access their fishing grounds for commercial purposes, and occupation were the most important predictors of whether someone would contribute.

Although the outcomes, contexts, and methods were diverse, there were several components of the social-ecological system that were consistently important across studies (Table 2). In particular, dependence on the resource, knowledge of the social ecological system, and property rights systems that allowed limited access were highlighted as important features in most or all of the studies. For example, the studies highlight the complicated role that dependence on resources plays in achieving different fishery outcomes. While previous studies have demonstrated that people more readily participate in collective action when they are directly involved in a given resource (Agrawal, 2001; Gelcich et al., 2007; Ostrom, 1990), this special issue uncovers important nuances in these relationships. The poor, for instance, can view co-management as being substantially more beneficial when they have diverse livelihoods while the wealthy may view co-management as detrimental to their livelihoods when their livelihoods are more diverse (MacNeil and Cinner, this issue). This suggests that investments in diverse livelihoods need to be appropriately targeted to poorer resource users to avoid perverse, negative outcomes.

The second key theme emerging from this special issue is highlighting the importance of allowing management systems to reflect the local context. Basurto highlight how there may be multiple pathways to averting fishery crises by describing how two nearby communities in Mexico achieved important sustainability objectives using very different techniques. Specifically, their case study from Mexico describes how three nearby communities can have dramatically different fisheries outcomes, despite targeting the same resource under similar ecological conditions. Specifically, two communities (Seri and Peñasco) developed local rules to limit overexploitation, though the types of management developed were very different. This highlights how there can be different paths toward governance or resource sustainability. Seri developed formal territorial use areas, while Peñasco developed a local network of marine reserves, yet the third community, Kino, failed to maintain effective rules to limit overexploitation.

Table 2

\begin{tabular}{|c|c|c|c|c|}
\hline $\begin{array}{l}\text { Study } \\
\text { Type of outcome }\end{array}$ & $\begin{array}{l}\text { Basurto et al. } \\
\text { Self-governance }\end{array}$ & $\begin{array}{l}\text { Earnst et al. } \\
\text { Sustainability }\end{array}$ & $\begin{array}{l}\text { MacNeil \& Cinner } \\
\text { Livelihood }\end{array}$ & $\begin{array}{l}\text { Aswani et al. } \\
\text { Cooperation }\end{array}$ \\
\hline \multicolumn{5}{|l|}{ Governance system (GS) } \\
\hline Collective choice rules & $\times$ & & $\times$ & \\
\hline Property rights & $\times$ & $\times$ & & $\times$ \\
\hline Multi-scale partnerships & $\times$ & $\times$ & & \\
\hline Clearly defined boundaries & & $\times$ & $\times$ & \\
\hline \multicolumn{5}{|l|}{ Resource system (RS) } \\
\hline Productivity & & $\times$ & & \\
\hline \multicolumn{5}{|l|}{ Actors (A) } \\
\hline Group size & & $\times$ & $\times$ & \\
\hline Socioeconomic attributes (wealth) & & & $\times$ & \\
\hline Socioeconomic attributes (age) & & & & $\times$ \\
\hline History of use & & & $\times$ & \\
\hline Leadership & $\times$ & & & \\
\hline Social capital & $\times$ & & & \\
\hline Knowledge of SES & $\times$ & $\times$ & $\times$ & \\
\hline Resource dependency & $\times$ & $\times$ & $\times$ & $\times$ \\
\hline
\end{tabular}


In a similar vein of needing to reflect local conditions, several of the articles also describe the potential perils of a panacea approach toward solving fisheries problems. Basurto et al. and Earnst et al. highlight how standard policy prescriptions can undermine existing management systems that have sustained resources and livelihoods for generations. For example, outside experts have routinely described the stock as overexploited and assumed there was a 'tragedy of the commons' unfolding in the Juan Fernandez Lobster fishery (Chile), often prescribing generic solutions such as quotas and marine protected areas. Yet a closer look reveals a detailed common property system already exists. Access to the fishery is controlled through a highly nuanced system of sea tenure. Earnst et al. take great pains to point out how these generic solutions are likely to undermine existing common property institutions and decrease sustainability. Basurto et al.'s case study from Chile examines a single community over time to highlight how national policies that don't reflect the local socioeconomic context can undermine existing sociocultural institutions and lead to overexploitation. Basurto et al. describe how a national comanaged TURF system ironically eroded a traditional territorial use rights system in which an annual lottery system provided individual use rights over specific harvesting grounds. In this case, the government of Chile introduced a co-management policy of Territorial Use Rights for Fishers (TURF), which undermined a traditional system of bull kelp harvesting that had sustainably harvested resources and provided the community with social and ecological benefits. Yet the TURF co-management system quickly eroded the traditional management system, resulting in overexploitation. Yet, Basurto et al. provide a glimmer of hope in this tale by highlighting how the community was able to recover its selforganizing capacity because the governance system maintained a degree of flexibility. Specifically, resource users and fisheries officials were eventually able to modify the TURF system to incorporate some key principles of the traditional management system.

The third key theme emerging from this special issue highlights the multi-scale nature of both problems and solutions in smallscale fisheries. MacNeil and Cinner tackle this topic by conducting a hierarchical analysis of variables operating at different scales to reveal how cross-scale interactions can influence how people perceive benefits from fisheries co-management. Specifically, they explore how cross-scale interactions between population size and dependence on marine resource use affect livelihood outcomes from co-management to reveal that the benefits of collective action have a curvilinear relationship to population size. Previous studies have found curvilinear relationships between group size and collective action outcomes (Agrawal and Goyal, 2001; Yang et al., 2013), but this is the first study to look specifically at how this interacts with wealth. In communities with small or large populations, co-management tends to benefit either the poor or rich, depending on whether people depend on marine resources as a primary or secondary occupation. For those who depend primarily on marine resources for their livelihoods, the wealthy benefit most in smaller populations, but the poor benefit in larger populations. However, in medium populations both the poor and wealthy benefit equally. Basurto et al. also highlight the importance of the multi-scale nature of problems and solutions by highlighting how cross-scale lessons and vertical interactions across stakeholders were required to achieve sustainable practices in Puertecillo, Chile, after the implementation of new policy prescriptions.

\section{Conclusion}

These articles reflect on the opportunities to be found in using Ostrom's social-ecological system framework as a common language for the combined analysis of social-ecological conditions. They provide insights into how social-ecological assessments can fulfill important objectives and inform contemporary fisheries management, while demonstrating how multiple causal pathways can achieve similar outcomes. This provides a clear counter narrative to prescriptive management approaches. Results highlight that a core challenge in diagnosing why some fisheries are sustainable while others collapse is the identification and analysis of relationships among multiple tiers within the framework. This special issue illustrates how the framework can productively accommodate a diversity of approaches and inform how particular factors and relationships might lead to outcomes of interest to researchers, practitioners, and policy makers alike.

\section{Acknowledgments}

Support for this work was provided by Australian Research Council and the Australian Institute of Marine Science. SG thanks Fondecyt grant 1120103 \& ICM P10-033F.

\section{References}

Agrawal, A., 2001. Common property institutions and sustainable governance of resources. World Development 29, 1649-1672.

Agrawal, A., Goyal, S., 2001. Group size and collective action - third-parts monitoring in common-pool resources. Comparative Political Studies 34, 63-93.

Allen, T.F., Starr, T.B., 1982. Hierarchy: Perspectives for Ecological Complexity. University of Chicago Press, Chicago.

Aswani, S., Gurney, G., Mulville, S., Matera, J., Gurven, M., this issue. Insights from experimental economics on local cooperation in a small-scale fishery management system. Global Environmental Change (this issue).

Basurto, X., 2005. How locally designed access and use controls can prevent the tragedy of the commons in a Mexican small-scale fishing community. Society \& Natural Resources 18, 643-659.

Basurto, X., Gelcich, S., Ostrom, E., this issue. The social-ecological system framework as a knowledge classificatory system for benthic small-scale fisheries. Global Environmental Change (this issue).

Berkes, F., Colding, J., Folke, C., 2003. Navigating Social-Ecological Systems: Building Resilience for Complexity and Change. Cambridge University Press, Cambridge, UK.

Berkes, F., Folke, C.E., 1998. Linking Social and Ecological Systems. Cambridge University Press, Cambridge.

Cinner, J.E., Daw, T.M., McClanahan, T.R., Muthiga, N., Abunge, C., Hamed, S. Mwaka, B., Rabearisoa, A., Wamukota, A., Fisher, E., Jiddawi, N., 2012a. Transitions toward co-management: the process of marine resource management devolution in three east African countries. Global Environmental Change 22, 651-658.

Cinner, J.E., McClanahan, T.R., MacNeil, M.A., Graham, N.A.J., Daw, T.M., Mukminin, A., Feary, D.A., Rabearisoa, A.L., Wamukota, A., Jiddawi, N., 2012b. Comanagement of coral reef social-ecological systems. Proceedings of the National Academy of Sciences of the United States of America 109, 5219-5222.

Cox, M., Arnold, G., Tomas, S.V., 2010. A review of design principles for community based natural resource management. Ecology and Society 15, 38.

Crona, B., Bodin, O., 2010. Power asymmetries in small-scale fisheries - a barrier to governance transformability? Ecology \& Society 15, 32.

Earnst, B., Chamorro, J., Manríquez, P., Orensanz, J.M.L., Parma, A.M., Porobic, J., Román, C., this issue. Sustainability of the Juan Fernández lobster fishery (Chile) and the perils of generic science-based prescriptions. Global Environmental Change (this issue).

Gelcich, S., Edwards-Jones, G., Kaiser, M.J., 2007. Heterogeneity in fishers' harvesting decisions under a marine territorial user rights policy. Ecological Economics 61, 246-254.

Gelcich, S., Edwards-Jones, G., Kaiser, M.J., Castilla, J.C., 2006. Co-management policy can reduce resilience in traditionally managed marine ecosystems. Ecosystems 9, 951-966.

Gelcich, S., Hughes, T.P., Olsson, P., Folke, C., Defeo, O., Fernandez, M., Foale, S., Gunderson, L.H., Rodriguez-Sickert, C., Scheffer, M., Steneck, R.S., Castilla, J.C., 2010. Navigating transformations in governance of Chilean marine coastal resources. Proceedings of the National Academy of Sciences of the United States of America 107, 16794-16799.

Gelman, A., Hill, J., 2007. Data Analysis Using Regression and Multilevel/Hierarchical Models. Cambridge University Press, Cambridge.

Gutierrez, N.L., Hilborn, R., Defeo, O., 2011. Leadership, social capital and incentives promote successful fisheries. Nature 470, 386-389.

Hilborn, R., Branch, T.A., Earnst, B., Magnusson, A., Minte-Vera, C.V., Scheuerell, M.D., Valero, J.L., 2003. State of the world's fisheries. Annual Review of Environment and Resources 28, 359 
Jackson, J.B.C., Kirby, M.X., Berger, W.A., Bjorndal, K.A., Botsford, L.W., Bourque, B.J., Bradbury, R.H., Cooke, R., Erlandson, J., Estes, J.A., Hughes, T.P., Kidwell, S., Lange, C.B., Lenihan, H.S., Pandolfi, J.M., Peterson, C.H., Steneck, R.S., Tegner, M.J., Warner, R.R., 2001. Historical overfishing and the recent collapse of coastal ecosystems. Science 293, 629-638.

MacNeil, M.A., Cinner, J., this issue. Hierarchical livelihood outcomes among comanaged fisheries. Global Environmental Change (this issue).

McClanahan, T.R., Castilla, J.C., White, A.T., Defeo, O., 2009. Healing small-scale fisheries by facilitating complex socio-ecological systems. Reviews in Fish Biology and Fisheries 19, 33-47.

McClanahan, T.R., Marnane, M.J., Cinner, J.E., Kiene, W.E., 2006. A comparison of marine protected areas and alternative approaches to coral-reef management. Current Biology 16, 1408-1413.

Mora, C., Sale, P.F., 2011. Ongoing global biodiversity loss and the need to move beyond protected areas: a review of the technical and practical shortcomings of protected areas on land and sea. Marine Ecology Progress Series 434, 251-266.

Myers, R.A., Worm, B., 2003. Rapid worldwide depletion of predatory fish communities. Nature 423, 280-283.

Ostrom, E., 1990. Governing the Commons: The Evolution of Institutions for Collective Action. Cambridge University Press, Cambridge, UK.

Ostrom, E., 2007. A diagnostic approach for going beyond panaceas. Proceedings of the National Academy of Sciences of the United States of America 104, 15181-15187.

Ostrom, E., 2008. The challenge of common-pool resources. Environment: Science and Policy for Sustainable Development 50, 8-21.

Ostrom, E., 2009. A general framework for analyzing sustainability of socialecological systems. Science 325, 419-422.

Ostrom, V., Ostrom, E., 1977. A theory for institutional analysis of common pool problems. In: Managing the Commons. W.H. Freeman, San Francisco, CA, pp. 157-172.

Rockström, J., Steffen, W., Noone, K., Persson, Å., Chapin, F.S., Lambin, E.F., Lenton, T.M., Scheffer, M., Folke, C., Schellnhuber, H.J., 2009. A safe operating space for humanity. Nature 461, 472-475.

Worm, B., Barbier, E.B., Beaumont, N., Duffy, J.E., Folke, C., Halpern, B.S., Jackson, J.B.C., Lotze, H.K., Micheli, F., Palumbi, S.R., Sala, E., Selkoe, K.A., Stachowicz, J.J., Watson, R., 2006. Impacts of biodiversity loss on ocean ecosystem services. Science 314, 789-790.
Yang, W., Liu, W., Viña, A., Tuanmu, M.-N., He, G., Dietz, T., Liu, J., 2013. Nonlinear effects of group size on collective action and resource outcomes. Proceedings of the National Academy of Sciences of the United States of America.

J.E. Cinner*

ARC Centre of Excellence for Coral Reef Studies, James Cook University, Townsville, QLD 4811, Australia

M. Aaron MacNeil

Australian Institute of Marine Science, PMB 3 Townsville MC, Townsville, QLD 4810, Australia

Xavier Basurto

Division of Marine Science and Conservation, Nicholas School of the Environment, Duke University, 135 Duke Marine Lab Road, Beaufort, NC 28516, USA

Stefan Gelcich

Laboratorio Internacional en Cambio Global E Centro de Conservación Marina, Departamento de Ecologia, Facultad de Ciencias Biologicas, Pontificia Universidad Catolica de Chile, Santiago, Chile

${ }^{*}$ Corresponding author. Tel.: +61 0747816751 ; fax: +610747816722

E-mail address: Joshua.cinner@jcu.edu.au (J.E. Cinner) 